\title{
Intoxicação espontânea por Cestrum intermedium em bovinos no Sudoeste do Estado do Paraná ${ }^{1}$
}

\author{
Angelica T.B. Wouters², Fabiana M. Boabaid², Tatiane T.N. Watanabe², Paulo M. Bandarra², \\ Gabriel L.F. Correa ${ }^{2}$, Flademir Wouters ${ }^{2}$, Raquel M. Mafessoni ${ }^{3}$ e David Driemeier ${ }^{2 *}$
}

\begin{abstract}
Wouters A.T.B., Boabaid F.M., Watanabe T.T.N., Bandarra P.M., Correa G.L.F., Wouters F., Mafessoni R.M. \& Driemeier D. 2013. [Spontaneous poisoning by Cestrum intermedium in cattle in Southwest of Paraná, Brazil.] Intoxicação espontânea por Cestrum intermedium em bovinos no Sudoeste do Estado do Paraná. Pesquisa Veterinária Brasileira 33(1):47-51. Setor de Patologia Veterinária, Faculdade de Veterinária, Universidade Federal do Rio Grande do Sul, Avenida Bento Gonçalves 9090, Porto Alegre, RS 91540-000, Brazil. E-mail: davetpat@ufrgs.br

Outbreaks of Cestrum intermedium poisoning affected cattle from dairy herds in Salgado Filho, Southwest of Paraná, southern Brazil, with death of sixteen from 72 animals of four small properties. The onset of the acute clinical signs and death within $24 \mathrm{~h}$ were reported. High animal density and many shrubs identified as $C$. intermedium that showed signs of having been consumed by the animals were noticed in all farms. Two animals were necropsied and the most important findings were congested conjunctival and vulvovestibular mucosae; hemorrhages and enhanced lobular pattern in the liver; hemorrhages, congestion and edema in the lung; splenic and brain congestion, and multifocal hemorrhages in the heart. Tissue samples from these two bovines were evaluated. Histological lesions were marked in the liver, such as severe centrolobular necrosis and hemorrhage, what is indicative of acute toxic liver disease. In the brain tissue, astrocytic changes were observed in the white matter of the cerebrum and cerebellum, and in the gray matter of the cerebellum. They were characterized by cell swelling with large and eosinophilic cytoplasm, pyknotic and sometimes eccentric nucleus. These astrocytic changes features were demonstrated by immunohistochemical techniques using the anti-S100 protein and anti-glial fibrillary acidic protein (GFAP), with a strongly positive immunostaining for both antibodies. The paper aims to emphasize on neurological lesions of acute hepatotoxicity in cattle.
\end{abstract}

INDEX TERMS: Poisonous plants, Cestrum intermedium, Solanaceae, liver, plant poisoning, diseases of cattle, immunohistochemistry.

RESUMO.- São descritos surtos de intoxicação espontânea por Cestrum intermedium em bovinos leiteiros do Município de Salgado Filho, sudoeste do Estado do Paraná, com morte de dezesseis bovinos de um total de 72 de quatro pequenas propriedades. $\mathrm{O}$ histórico obtido nessas propriedades incluía curso clínico agudo, com morte em menos de 24 horas. Em todas foram observadas elevada lotação por

\footnotetext{
${ }^{1}$ Recebido em 28 de setembro de 2012.

Aceito para publicação em 19 de outubro de 2012.

${ }^{2}$ Departamento de Patologia Clínica Veterinária, Faculdade de Veterinária, Universidade Federal do Rio Grande do Sul (UFRGS), Av. Bento Gonçalves 9090, Porto Alegre, RS 95320-000, Brasil. *Autor para correspondência: davetpat@ufrgs.br

${ }^{3}$ Médica Veterinária, Rua Pato Branco 482, Francisco Beltrão, PR 85601350, Brasil.
}

área com escassa pastagem disponível e grande quantidade de plantas arbustivas identificadas como $C$. intermedium e com sinais de terem sido consumidas pelos animais. Dois bovinos foram necropsiados e os achados mais importantes foram congestão de mucosas conjuntivais e vulvovestibular; hemorragias e evidenciação do padrão lobular no fígado; hemorragia, congestão e edema pulmonares; congestão esplênica e encefálica, além de hemorragias multifocais no coração. Amostras de tecidos desses bovinos foram avaliadas, com alterações histológicas importantes no fígado, caracterizadas por necrose acentuada de hepatócitos e hemorragia, indicativas de hepatopatia tóxica aguda e, no encéfalo, foram observadas alterações astrocitárias em substância branca de cérebro e cerebelo e na substância cinzenta do cerebelo, caracterizadas por tumefação celular 
com citoplasma amplo e eosinofílico, núcleo picnótico, ora excêntrico. Essas alterações astrocitárias foram evidenciadas pela técnica de imuno-histoquímica (IHQ), com imunomarcação fortemente positiva para os anticorpos anti-proteína S100 (anti-S100) e anti-proteína glial fibrilar ácida (anti-GFAP). 0 trabalho visa enfatizar em lesões encefálicas relacionadas à hepatotoxicidade aguda em bovinos.

TERMOS DE INDEXAÇ̃̃O: Plantas tóxicas, Cestrum intermedium, Solanaceae, fígado, intoxicação por plantas, doença de bovinos, imuno-histoquímica.

\section{INTRODUÇÃO}

Cestrum intermedium, planta arbustiva a arbórea pertencente a um gênero tipicamente americano da Família Solanaceae, está presente no Brasil, de Minas Gerais até o Rio Grande do Sul. A espécie ocorre tanto no interior quanto em borda de matas e também em locais antropizados (Soares et al. 2007), como beiras de cercas, áreas destinadas a pastagens e em terrenos baldios (Lorenzi 2008b). É conhecida pelos nomes populares de "coerana", "mata-boi" e "peloteira preta" (Kissmann \& Groth 2000, Lorenzi 2008b).

C. intermedium causa intoxicação em bovinos em situações de escassez de forragem, principalmente no inverno, em períodos de seca ou quando há lotação animal elevada nas pastagens (Tokarnia et al. 2012). É considerada a planta tóxica de maior importância no extremo oeste e no noroeste do Estado de Santa Catarina (Gava 1993, Gava et al. 1996). Furlan et al. (2008) descreveram um surto de intoxicação espontânea por $C$. intermedium em bovinos no Município de Jupiá, oeste de Santa Catarina. Casos de intoxicação são também descritos em bovinos no Rio Grande do Sul, na região da encosta da Serra Gaúcha (Bandarra et al. 2009).

O quadro clínico da intoxicação por $C$. intermedium é curto, de aproximadamente 12 a 48 horas (Gava et al. 1996) e há observação de curso clínico até inferior a 12 horas (Bandarra et al. 2009). As manifestações clínicas são de insuficiência hepática aguda, com anorexia, atonia ruminal, fezes escassas, ressecadas e com muco e/ou sangue, congestão conjuntival (Gava et al. 1996), tremores musculares, incoordenação (Gava et al. 1996, Furlan et al. 2008, Bandarra et al. 2009), agressividade (Furlan et al. 2008, Bandarra et al. 2009), pressão da cabeça contra obstáculos, cabeça voltada para o flanco, gemidos (Gava et al. 1996), decúbito esternal (Gava et al. 1996, Furlan et al. 2008) e lateral (Furlan et al. 2008, Bandarra et al. 2009), movimentos de pedalagem (Gava et al. 1996, Furlan et al. 2008), opistótono e morte (Gava et al. 1996).

Os achados de necropsia mais importantes em bovinos intoxicados por $C$. intermedium estão no fígado, o qual apresenta evidenciação do padrão lobular (Furlan et al. 2008, Bandarra et al. 2009) e pode ter seu volume aumentado (Bandarra et al. 2009). São descritos edema da parede da vesícula biliar (Gava et al. 1996, Bandarra et al. 2009) e da porção inicial do duodeno (Gava et al. 1996), retração do globo ocular por desidratação, hemorragias em tecido subcutâneo (Bandarra et al, 2009), coração (Gava et al. 1996, Bandarra et al, 2009), intestino grosso (Gava et al.
1996), timo, tireoide, serosa do rúmen, omento e mesentério (Bandarra et al. 2009) e ressecamento do conteúdo de omaso, cólon e reto (Gava et al. 1996).

Há, no Brasil, diversas espécies de plantas tóxicas cuja ingestão resulta em lesão hepática caracterizada histologicamente por necrose acentuada de hepatócitos, incluindo Cestrum spp. e outras plantas hepatotóxicas. Além das plantas, deve ser também considerada a possibilidade de intoxicação por larvas do inseto Perreyia flavipes, descrita em bovinos e ovinos no Sul do Brasil, com ingestão das larvas nas pastagens, principalmente no período de maio a setembro (Soares et al., 2008, Raymundo et al. 2009).

São descritos quatro surtos de intoxicação por $C$. intermedium em bovinos do sudoeste do Estado do Paraná, com avaliação histológica dos tecidos e realização da técnica de IHQ para os anticorpos anti-S100 e anti-GFAP em cérebro e cerebelo.

\section{MATERIAL E MÉTODOS}

Foram realizadas avaliação macroscópica e histológica de tecidos colhidos na necropsia de dois bovinos, fêmeas, mestiças, uma com aproximadamente 6 anos (Propriedade A) e outra com 1 ano e 4 meses (Propriedade B) e visita a quatro propriedades (Proprieda$\operatorname{des} A, B, C$ e D) para investigação da ocorrência de agentes hepatotóxicos e coleta de dados.

Cortes de $3 \mu \mathrm{m}$ de espessura foram efetuados dos blocos em parafina de cérebro e cerebelo para a realização da técnica de IHQ pelo método estreptavidina-biotina ligada à peroxidase, usando os anticorpos primários (anti-GFAP) e (anti-S100). 0 bloqueio da atividade da peroxidase endógena foi realizado com a incubação dos cortes dos tecidos em solução 10\% de peróxido de hidrogênio (30 vol.), em metanol, durante 10 minutos. Para a recuperação antigênica, utilizou-se tampão tris EDTA, pH 9,0, e tampão citrato, pH 6,0, em panela de pressão a $96^{\circ} \mathrm{C}$, por 40 minutos (anticorpo policlonal anti-GFAP, Z0334, DakoCytomation, diluição 1:500 e anticorpo policlonal anti-S100, Z0311, DakoCytomation, diluição 1:200, respectivamente). Os anticorpos primários foram diluídos em solução salina tamponada com fosfato (PBS), aplicados nas lâminas e incubadas em câmara úmida por 14-16 horas ("overnight") a $4^{\circ}$ C. Posteriormente, os cortes foram incubados com anticorpo secundário biotinilado ligado a estreptavidina-peroxidase (kit LSAB-HRP, K0690, DakoCytomation), 20 minutos cada etapa. A reação para GFAP foi revelada com 3,3-diaminobenzidina (DAB, DakoCytomation) e, para S100, foi usado o cromógeno VECTOR ${ }^{\circledR}$ NovaRed. Para a contracoloração utilizou-se hematoxilina de Harris, seguida da montagem em Entellan ${ }^{\circledR}$. Como controles para avaliação das imunomarcações anti-GFAP e anti-S100 foram usados cortes de telencéfalo, tronco encefálico e cerebelo de bovinos adultos da rotina de diagnóstico do Setor de Patologia Veterinária da Universidade Federal do Rio Grande do Sul (SPV-UFRGS) sem alterações hepáticas e/ou encefálicas e como controle negativo cortes correspondentes incubados apenas com PBS.

\section{RESULTADOS}

Quatro pequenas propriedades localizadas no Município de Salgado Filho, sudoeste do Paraná, apresentaram mortalidade de bovinos leiteiros. Na Propriedade A morreram, em um período de 40 dias do inverno de 2008, quatro animais adultos de um plantel de 19 bovinos. 0 plantel era mantido em 3,0 ha de campo e aproximadamente 1,0 ha de pastagem cultivada, com fornecimento de cana-de-açúcar e 
forragem em cocho. As manifestações clínicas observadas incluíram escoicear do ventre e movimentos de pedalagem, já em decúbito lateral, com morte em menos de 24 horas. $\mathrm{Na}$ necropsia foram constatados bom estado corporal, mucosas conjuntivais e vulvovestibular, fígado, baço e cérebro congestos e hemorragias focais em pulmões e coração.

Na Propriedade B haviam morrido quatro de 28 bovinos de um mesmo piquete, também no inverno de 2008 e, em 2009, morreu mais uma vaca, com manifestações clínicas semelhantes. Estas incluíam fraqueza, dispneia, permanência em estação com o pescoço estirado, balançar da cabeça e berros fortes. 0 período da observação dos primeiros sinais clínicos até a morte foi inferior a 24 horas em todos os casos. No bovino necropsiado havia evidenciação do padrão lobular no fígado, vesícula biliar repleta; pulmões congestos e edematosos, linfonodos mediastínicos aumentados de volume, baço congesto e, no coração, havia hemorragias multifocais subendocárdicas e subepicárdicas.

Na Propriedade C, morreram, em um período de 72 horas, cinco de 18 bovinos em outubro de 2011, sendo quatro fêmeas de 7-8 meses de idade e um macho, com relato de evolução clínica de aproximadamente 12 horas até a morte. Os animais estavam em um campo com pasto escasso. $\mathrm{Na}$ quarta propriedade (Propriedade D), foram encontradas mortas duas vacas de um plantel de 7 bovinos.

Em visita às propriedades foi verificada grande quantidade de plantas da espécie $C$. intermedium no local em que os bovinos eram mantidos, com sinais de folhas consumidas (Fig.1).

Na avaliação histológica do fígado do bovino da Propriedade A foi observada necrose aguda difusa acentuada de hepatócitos, associada a hemorragia acentuada (Fig.2), poupando apenas hepatócitos da periferia dos lóbulos. Havia discreto infiltrado inflamatório nas áreas de necrose, composto predominantemente por neutrófilos, e ocasionais células de Kupffer apresentavam citoplasma carregado de pigmento granular acastanhado. Foram ainda observadas hemorragia multifocal nos pulmões e congestão no baço. No outro bovino (Propriedade B) foi também observada necrose aguda acentuada de hepatócitos, no entanto, com distribuição centrolobular e havia vacuolização difusa

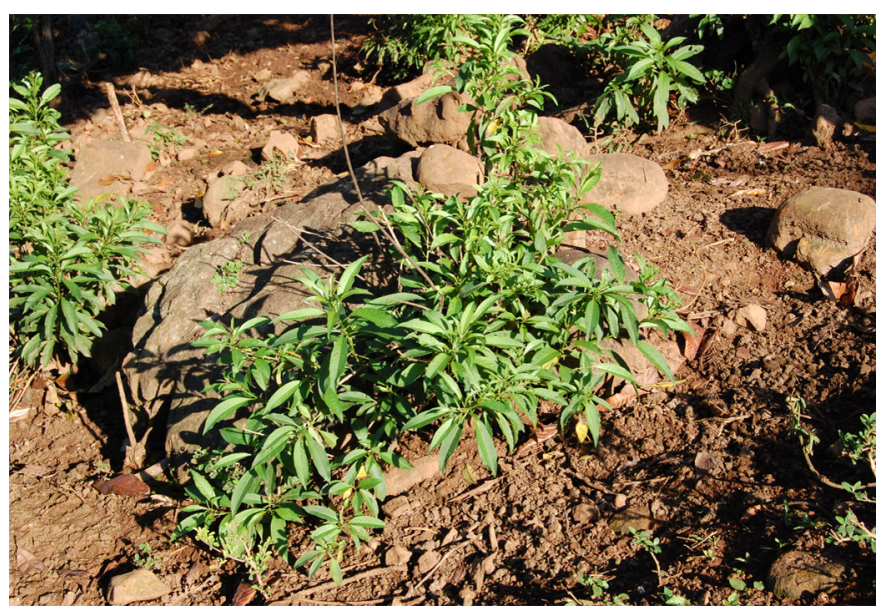

Fig.1. Arbusto de Cestrum intermedium em brotação. Observam-se galhos cujas folhas foram consumidas. discreta do citoplasma dos hepatócitos periféricos à necrose, entremeados por ocasionais glóbulos eosinofílicos. Hemorragia e infiltrado inflamatório estavam também presentes no fígado, com intensidade e distribuição similares ao primeiro animal. Na substância branca do cérebro e do cerebelo de ambos os bovinos foram observados astrócitos com citoplasma amplo e fraca e homogeneamente eosinofílico, núcleo retraído com cromatina densa, excêntrico em algumas células (Fig.3). Em alguns cortes havia também vacuolização arredondada multifocal discreta da substância branca. Astrócitos de Bergmann no cerebelo apresentavam aspecto semelhante aos astrócitos da substância branca. Havia ainda congestão difusa discreta a moderada no cérebro e no cerebelo dos dois bovinos e, no exame dos demais órgãos; hemorragia focal no miocárdio, congestão pulmonar, além de áreas de enfisema e atelectasia (Bovino Propriedade A); depleção linfoide moderada em linfonodo,

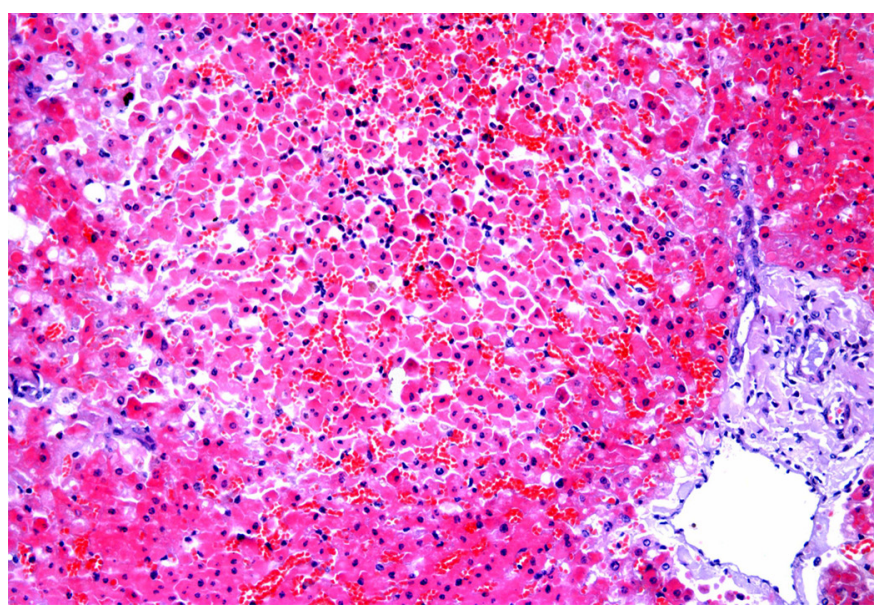

Fig.2. Fígado de bovino (Propriedade A) intoxicado por Cestrum intermedium. Observa-se necrose coagulativa acentuada de hepatócitos associada a hemorragia, poupando apenas hepatócitos periportais. Há discreto infiltrado inflamatório, composto predominantemente por neutrófilos. HE, obj.20x.

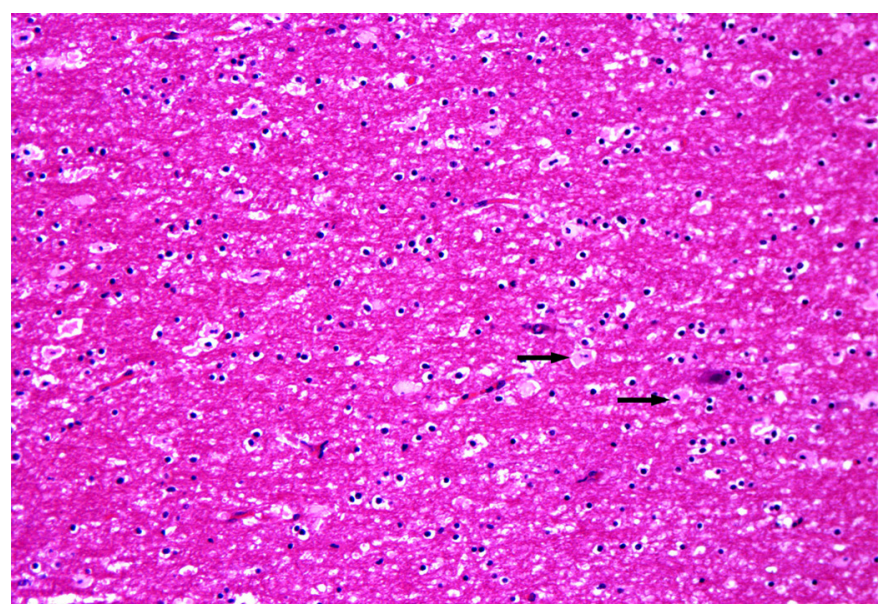

Fig.3. Telencéfalo de bovino (Propriedade B) intoxicado por Cestrum intermedium. Astrócitos da substância branca subcortical com citoplasma amplo, fraca e homogeneamente eosinofílico e núcleo retraído e excêntrico com cromatina densa (setas). HE, obj.20x. 
necrose discreta em centros foliculares e hemossiderose difusa discreta no baço, congestão pulmonar e edema alveolar e intersticial acentuado (Bovino Propriedade B).

$\mathrm{Na}$ avaliação por IHQ, as alterações observadas em astrócitos na coloração de rotina foram evidenciadas nas imunomarcações anti-GFAP e anti-S100, com marcação citoplasmática positiva acentuada nos astrócitos da substância branca do cérebro e do cerebelo (Fig. 4) e os astrócitos de Bergmann, no cerebelo. Em vacúolos arredondados formados na substância branca, observados nos cortes submetidos ao anticorpo anti-S100, havia marcação positiva nas bordas, delimitando esses vacúolos.

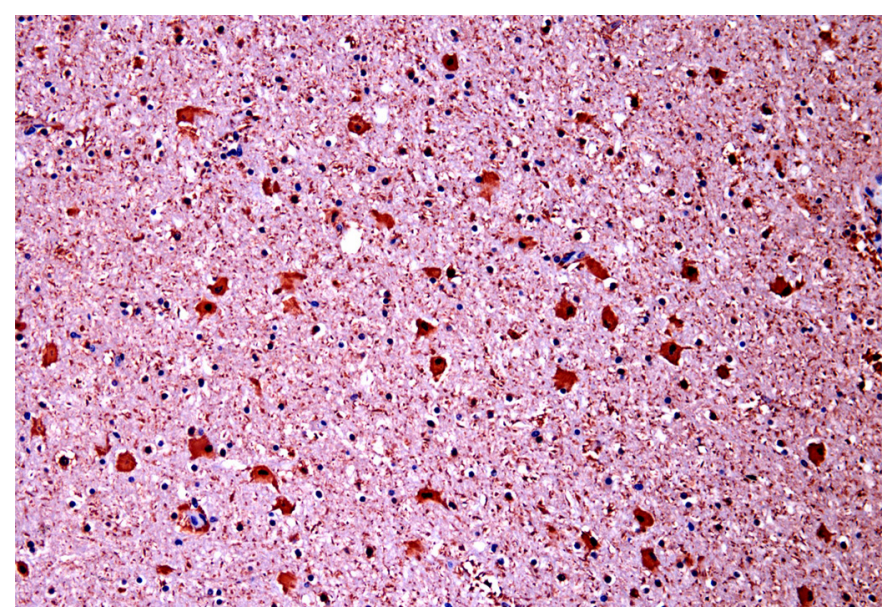

Fig.4. Imunomarcação anti-S100 em substância branca telencefálica de bovino (Propriedade B) intoxicado por Cestrum intermedium, evidenciando astrócitos com citoplasma amplo, fortemente marcado em castanho e núcleo retraído. Método da Estreptavidina-biotina-peroxidase. Cromógeno Vector Nova Red, contracoloração Hematoxilina de Harris, obj. 20x.

\section{DISCUSSÃO E CONCLUSÕES}

Cestrum intermedium, planta identificada como tóxica para bovinos em Santa Catarina e com grande importância no Extremo Oeste e no Noroeste desse Estado (Gava, 1993, Gava et al. 1996), foi a causa de intoxicação espontânea em bovinos no sudoeste do Estado do Paraná, caracterizada por insuficiência hepática aguda, com necrose acentuada de hepatócitos.

Em uma das propriedades foram encontrados bovinos mortos sem que sinais clínicos fossem percebidos. Provavelmente os animais tiveram manifestação clínica, porém breve e que não foi observada; o que indica rápida evolução para a morte. Bandarra et al. (2009) observaram curso clínico inferior a 12 horas em um surto de intoxicação natural por $C$. intermedium em bovinos. 0 quadro clínico de evolução aguda está relacionado à instalação de insuficiência hepática aguda e, na intoxicação por plantas com esse efeito, a taxa de mortalidade pode atingir 70 a $100 \%$ (Riet-Correa et al. 2009).

As alterações histológicas foram constituídas por necrose acentuada de hepatócitos, com variação na extensão da lesão nos lóbulos dos fígados avaliados. Nos casos de evolução clínica mais rápida é esperada lesão difusa nos lóbulos, com morte em 12 a 24 horas após a ingestão da planta hepatotóxica, e predominantemente centrolobular naqueles de evolução mais longa, isto é, superior a 24h. (Riet-Correa et al. 2009). No exame histológico em outros casos de intoxicação por $C$. intermedium são descritos no fígado necrose coagulativa centrolobular (Gava et al. 1996, Bandarra et al. 2009) e em zona intermediária a massiva, difusa, aguda e acentuada, acompanhada por congestão centrolobular (Gava et al. 1996) e degeneração vacuolar em hepatócitos adjacentes (Gava et al. 1996, Furlan et al. 2008, Bandarra et al. 2009).

0 discreto infiltrado inflamatório observado nas áreas de necrose de hepatócitos foi interpretado como resposta do organismo às células necróticas. Bandarra et al. (2009) também descreveram infiltrado inflamatório discreto, composto por neutrófilos e macrófagos, nas áreas de necrose hepática, em espaços porta e lúmen de ductos biliares, além de hemorragia em coração, timo e tireoide e hemossiderose difusa moderada no baço.

Na propriedade B foi verificada doença clínica, no entanto, a conclusão diagnóstica só foi possível após constatação da alteração histológica de necrose acentuada de hepatócitos associada a hemorragia, lesão característica de hepatopatia tóxica aguda em ruminantes, aliada à confirmação "in loco" da ocorrência de C. intermedium em grandes quantidades nas áreas ocupadas por bovinos. Esse fato evidencia a importância do exame de necropsia, da colheita de amostras de órgãos e da realização do exame histológico para o diagnóstico. Muitas intoxicações por planta induzem alterações morfológicas mais ou menos características, sendo o exame histológico um meio complementar muito útil na confirmação diagnóstica (Tokarnia et al. 2012).

Os achados de evidenciação do padrão lobular do fígado e hemorragias multifocais a difusas em fígado e serosas na intoxicação por $C$. intermedium são também descritos em outras hepatopatias tóxicas agudas em bovinos no Brasil (Santos et al. 2008, Riet-Correa et al. 2009, Tokarnia et al. 2012), como na intoxicação por C. corymbosum (Gava et al. 1991, Varaschin et al. 2011), C. laevigatum (Döbereiner et al. 1969), C. parqui (Riet-Correa et al. 1986), Dodonaea viscosa (Colodel et al. 2003), Myoporum laetum (Méndez 1993), Sessea brasiliensis (Canella et al. 1968), Vernonia mollissima (Döbereiner et al. 1976), Vernonia rubricaulis (Tokarnia \& Döbereiner 1982, Brum et al. 2002) e Xanthium strumarium, também identificado como Xanthium cavanillesii (Méndez et al. 1998, Driemeier et al. 1999); de forma que devem ser consideradas no diagnóstico diferencial. Dessas plantas, são registradas no estado do Paraná, além de $C$. intermedium, as plantas hepatotóxicas $C$. corymbosum (Kissmann \& Groth 2000, Lorenzi 2008a), Trema micrantha (Lorenzi 2008b) Xanthium strumarium (Kissmann \& Groth 2000, Tokarnia et al. 2012). Na intoxicação por larvas de Perreyia flavipes observam-se, além da necrose hepática, necrose linfoide em placas de Peyer, linfonodos mesentéricos e baço (Soares et al. 2008, Raymundo et al. 2009). Doenças que cursam com manifestações neurológicas, como a raiva, devem também ser consideradas no diagnóstico diferencial da intoxicação por plantas de ação hepatotóxica. Outrossim, a visita a propriedades com suspeita e/ou casos de intoxicação, a verificação da presença da provável planta tóxica com evidências de ter sido consumida pelos animais e a coleta de dados clínicos e epidemiológicos são funda- 
mentais para a diferenciação entre as diversas causas de hepatotoxicidade aguda de bovinos (Tokarnia et al. 2012).

Alterações histológicas foram observadas no encéfalo dos bovinos intoxicados por $C$. intermedium dos quais foram enviadas amostras para exame. Nas intoxicações por diferentes espécies de plantas hepatotóxicas de ação aguda estudadas em bovinos no Brasil tem sido observados danos encefálicos, em alguns casos inclusive com alterações macroscópicas e achados histológicos (Traverso et al. 2004, Varaschin et al. 2011), cuja patogenia não está definida até então. No entanto, nos presentes casos foram evidenciadas alterações degenerativonecróticas significativas em astrócitos de substância branca do cérebro e do cerebelo e nos astrócitos de Bergmann.

A técnica de IHQ foi empregada para avaliar melhor as alterações histológicas no encéfalo. Tanto a imunomarcação anti-GFAP quanto a anti-S100 apresentaram marcação positiva acentuada no citoplasma de astrócitos, evidenciando essas alterações. Os achados indicam que, nos casos de encefalopatia hepática aguda, os astrócitos são alvo de lesão; eles apresentaram, além das características degenerativonecróticas, as proteínas S100 e GFAP, com marcação muito maior que em astrócitos de animais controle, não afetados por encefalopatia hepática aguda. Isto sugere o aumento da quantidade dessas proteínas e/ou da sua expressão nos astrócitos nos casos de encefalopatia hepática aguda.

Em bovinos da Região Sul do Brasil é frequente a ocorrência de encefalopatia relacionada a hepatopatia crônica, relacionada principalmente à ingestão de Senecio spp. (Rissi et al. 2007, Lucena et al. 2010), com manifestações clínicas neurológicas, consistentemente associadas à observação de alterações histológicas encefálicas descritas como degeneração esponjosa ("status spongiosus"), relacionadas a edema intramielínico (Barros, 2010). Mais estudos devem ser conduzidos para a caracterização das alterações encefálicas nos casos de hepatopatia tóxica aguda em bovinos.

\section{REFERÊNCIAS}

Barros C.S.L. 2010. Fígado, vias biliares e pâncreas exócrino, p.183-290. In: Santos R.L. \& Alessi A.C. (Eds), Patologia Veterinária. Roca, São Paulo. 892p.

Bandarra P.M., Bezerra Júnior P.S., Corrêa A.M.R., Pedroso P.M.O., Raymundo D.L. \& Driemeier D. 2009. Intoxicação natural por Cestrum intermedium em bovinos no Rio Grande do Sul, Brasil. Ciência Rural 39(1):262-265.

Brum K.B., Purisco E., Lemos R.A.A. \& Riet-Correa F. 2002. Intoxicação por Vernonia rubricaulis em bovinos no Mato Grosso do Sul. Pesq. Vet. Bras. 22:119-128.

Canella C.F.C., Tokarnia C.H. \& Döbereiner J. 1968. Intoxicação por Sessea brasiliensis Toledo em bovinos. Pesq. Agrop. Bras. 3:333-340.

Colodel E.M., Traverso S.D., Seitz A.I., Oliveira E.N., Driemeier D. \& Gava A. 2003. Spontaneous poisoning by Dodonea viscosa (Salpindaceae) in cattle. Vet. Hum. Toxicol. 45(3):147-148.

Döbereiner J., Tokarnia C.H. \& Canella C.F. 1969. Intoxicação por Cestrum laevigatum Schlecht., a causa de mortantades em bovinos no Estado do Rio de Janeiro. Pesq. Agrop. Bras. 4:165-193.

Döbereiner J., Tokarnia C.H. \& Purisco E. 1976. Vernonia mollissima, planta tóxica responsável por mortandade de bovinos no Sul do Mato Grosso. Pesq. Agropec. Bras., Sér. Vet. 11:49-58.

Driemeier D., Irigoyen L.F., Loretti A.P., Colodel E.M. \& Barros C.S.L. 1999. Intoxicação espontânea pelos frutos de Xanthium cavanillesii (Asteraceae) em bovinos no Rio Grande do Sul. Pesq. Vet. Bras. 19(1):12-18.
Furlan F.H., Lucioli J., Borelli V., Faria Junior O.O., Rebelatto S.V., Gava A. \& Traverso S.D. 2008. Intoxicação por Cestrum intermedium (Solanaceae) em bovinos no Estado de Santa Catarina, Acta Scient. Vet. 36(3):281284.

Gava A. 1993. Intoxicação por Cestrum intermedium, p.72-74. In: Riet-Correa F., Méndez M.C. \& Schild A.L. (Eds), Intoxicações por Plantas e Micotoxicoses em Animais Domésticos. Hemisfério Sul, Pelotas. 340p.

Gava A., Stolf L., Pilati C., Neves D.S. \& Viganó L. 1991. Intoxicação por Cestrum corymbosum var. hirsutum (Solanaceae) em bovinos no Estado de Santa Catarina. Pesq. Vet. Bras. 11(3/4):71-74.

Gava A., Stolf L., Varaschin M.S., Neves D.S., Tigre A.P. \& Lesmann F. 1996. Intoxicação por Cestrum intermedium (Solanaceae) em bovinos. Pesq. Vet. Bras. 6:7-20.

Kissmann K.G. \& Groth D. 2000. Plantas Infestantes e Nocivas. Vol.3. 2ª ed. BASF, São Paulo. 722p.

Lorenzi H. 2008a. Árvores do Brasil. Vol.1. 5a ed. Instituto Plantarum, Nova Odessa. 384p.

Lorenzi H. 2008b. Plantas Daninhas do Brasil. 4aㅡ ed. Instituto Plantarum, Nova Odessa. 640p.

Lucena R.B., Rissi D.R., Maia L.A., Dantas A.F.M., Flores M.A., Nobre V.M.T., Riet-Correa F. \& Barros C.S.L. 2010. Intoxicação por alcaloides pirrolizidínicos em ruminantes e equinos no Brasil. Pesq. Vet. Bras. 30(5):447452.

Méndez M.C. 1993. Intoxicação por Myoporum spp., p.79-84. In: Riet-Correa F., Méndez M.C. \& Schild A.L. (Eds), Intoxicações por Plantas e Micotoxicoses em Animais Domésticos. Hemisfério Sul, Pelotas. 340p.

Méndez M.C., Santos R.C. \& Riet-Correa F. 1998. Intoxication by Xanthium cavanillesii in cattle and sheep in Southern Brazil. Vet. Hum. Toxicol. 40(3):144-147.

Raymundo D.L., Bezerra Junior P.S., Bandarra P.M., Santos A.S., Sonne L., Pavarini S.P., Corrêa A.M.R., Dias M.M. \& Driemeier D. 2009. Intoxicação espontânea pelas larvas de Perreyia flavipes em bovinos no Estado de Santa Catarina, Brasil. Ciência Rural 39(1):163-166.

Riet-Correa F., Schild A.L., Mendez M.C. \& Pinheiro M.H. 1986. Intoxicação por Cestrum parqui (Solanaceae) em bovinos no Rio Grande do Sul. Pesq. Vet. Bras. 6(4):111-115.

Riet-Correa F., Medeiros R.M.T., Pfister J., Schild A.L. \& Dantas A.F.M. 2009. Poisonings by Plants, Mycotoxins and Related Substances in Brazilian Livestock. UFCG, Campina Grande, PB. 246p.

Rissi D.R., Rech R.R., Pierezan F., Gabriel A.L., Trost M.E., Brum J.S., Kommers G.D. \& Barros C.S.L. 2007. Intoxicações por plantas e micotoxinas associadas a plantas em bovinos no Rio Grande do Sul: 461 casos. Pesq. Vet. Bras. 27:261-268.

Santos J.C.A., Riet-Correa F., Simões S.V.D. \& Barros C.S.L. 2008. Patogênese, sinais clínicos e patologia das doenças causadas por plantas hepatotóxicas em ruminantes e equinos no Brasil. Pesq. Vet. Bras. 28(1):1-14.

Soares E.L.C., Vignoli-Silva M. \& Mentz L.A. 2007. 0 gênero Cestrum L. (Solanaceae) no Rio Grande do Sul. Pesquisas, Botânica, São Leopoldo, 58:263-281.

Soares M.P., Quevedo P.S. \& Schild A.L. 2008. Intoxicação por larvas de Perreyia flavipes em bovinos na Região Sul do Rio Grande do Sul. Pesq. Vet. Bras. 28(3):169-173.

Tokarnia C.H. \& Döbereiner J. 1982. Intoxicação de bovinos por Vernonia rubricaulis (Compositae) em Mato Grosso. Pesq. Vet. Bras. 2(4):143-147.

Tokarnia C.H., Brito M.F., Barbosa J.D., Peixoto P.V. \& Döbereiner J. 2012. Plantas Tóxicas do Brasil para Animais de Produção. Editora Helianthus, Rio de Janeiro.

Traverso S.D., Corrêa A.M.R., Schmitz M., Colodel E.M. \& Driemeier D. 2004. Intoxicação experimental por Trema micrantha (Ulmaceae) em bovinos. Pesq. Vet. Bras. 24(4):211-216.

Varaschin M.S., Wouters F., Petta I., Bezerra Júnior P.S. \& Wouters A.T.B. 2011. Natural and experimental poisoning of bovines by Cestrum corymbosum Schlecht in the State of Minas Gerais, Brazil, p.227-230. In: Riet-Correa F., Pfister J., Schild A.L. \& Wierenga T.L. (Eds), Poisoning by Plants, Mycotoxins, and related Toxins. CABI, Wallingford, Oxfordshire. 739 p. 